\title{
ABSORÇÃO DE SUBDOSES GLYPHOSATE APLICADAS EM DIFERENTES LOCAIS DE PLANTAS DE EUCALIPTO ${ }^{1}$
}

\author{
Maria Renata Rocha Pereira ${ }^{2}$, Andreia Cristina Peres Rodrigues ${ }^{3}$, Caio Ferraz de Campos ${ }^{4}$, André Luiz \\ Melhorança Filho ${ }^{5}$ e Dagoberto Martins ${ }^{6}$
}

\begin{abstract}
RESUMO - Um dos grandes problemas enfrentados em áreas de reflorestamento com o cultivo de eucalipto são as plantas daninhas, cujo manejo assume papel de destaque entre os tratos culturais e com reflexos diretos no rendimento e nos custos de produção. Trabalhos preliminares de pesquisa e observação de campo apontam para uma tolerância diferencial ao glyphosate entre os locais (folhas e caule) que este herbicida atinge. Nesse contexto, este trabalho teve como objetivo verificar a intoxicação e o desenvolvimento de plantas submetidas a subdoses de glyphosate e sua absorção em diferentes locais de aplicação na planta, simulando uma deriva. O experimento foi conduzido em casa de vegetação, em um esquema fatorial, sendo quatro subdoses de glyphosate (40; 80; 160 e $240 \mathrm{~g} \mathrm{ha}^{-1}$ ) e três locais de aplicação (folha, caule e da planta inteira), além de uma testemunha sem a aplicação de herbicidas. O herbicida glyphosate causou fitointoxicação à cultura do eucalipto, sendo crescente com o aumento das subdoses e com maior intensidade nas aplicações sobre o caule e a planta inteira, atingindo $75 \%$ aos 14 dias após aplicação. O ganho em altura de plantas e em diâmetro, em massa seca da parte aérea e da área foliar teve reduções significativas, que resultaram em perdas de até 58\% na massa seca, $56 \%$ na área foliar e uma diferença de $6 \mathrm{~cm}$ no ganho em altura.
\end{abstract}

Palavras-chave: Fitotoxicidade, Tecnologia de aplicação, Herbicida e Deriva.

\section{GLYPHOSATE SUBDOSES ABSORTION APPLIED AT DIFFERENT LOCATIONS OF EUCALYPTUS PLANT}

\begin{abstract}
One of the biggest problems faced in reforestation areas with the eucalyptus crops are the weeds, whose management takes an important role among the cultural treatments and with direct responses in income and production costs. Preliminary works of research and field observations indicate a differential tolerance to glyphosate between local (leaves and stems) that this herbicide reaches. In this context, the objective of this work was to verify the intoxication and development of plants submitted to subdoses of glyphosate and its absorption in different application locals in the plant, simulating a drift. The experiment was conducted in a greenhouse, in a factorial arrangement, with four glyphosate subdoses (40, 80, 160 and $\left.240 \mathrm{~g} \mathrm{ha}^{-1}\right)$, and three application sites (leaf, stem and whole plant) and a control without application of herbicide. The glyphosate herbicide caused phytotoxicity in the eucalyptus crop, which increased as subdoses increased and with the greater intensity in the applications on the stem and whole plant, reaching $75 \%$ at 14 days after application. The gain in height plant and diameter, dry mass in the aerial section and leaf section had significant reductions, which resulted in losses up to 58\% in dry mass, 56\% in leaf area and a difference by $6 \mathrm{~cm}$ in height.
\end{abstract}

Keywords: Drift, Herbicide, Phytotoxicity and Technology of application.

\footnotetext{
${ }^{1}$ Recebido em 17.02.2009 e aceito para publicação em 18.04.2011.

${ }^{2}$ Programa de Pós-Graduação em Agronomia pela Faculdade de Ciências Agronômicas, Unesp, Botucatu-SP, Brasil. E-mail:<mariarenata10@hotmail.com>.

${ }^{3}$ Universidade Estadual do Oeste do Paraná, UNIOESTE, Brasil. E-mail: <andreiacpr@hotmail.com>.

${ }^{4}$ Faculdade de Ciências Agronômicas, Unesp, Botucatu, Brasil. E-mail: <caio.agro@hotmail.com>.

${ }^{5}$ Universidade Federal do Acre, UFAC, Brasil. E-mail: <andreluizdourados@hotmail.com>.

${ }^{6}$ Universidade Estadual Paulista Júlio de Mesquita Filho, UNESP, Brasil. E-mail: <dmartins@fca.unesp.br>.
} 


\section{INTRODUÇÃO}

O cultivo de espécies florestais sofre normalmente grande interferência das plantas daninhas, pois estas competem por água, luz e nutrientes, e podem, ainda, apresentar efeitos alelopáticos. Plantas invasoras representam prejuízo para o crescimento do eucalipto e uma ameaça para a sobrevivência das espécies nativas em reflorestamentos. A redução na produtividade, o elevado custo de controle, a grande demanda de mão de obra e o impacto do controle químico no ambiente colocam as plantas daninhas na lista dos piores problemas da eucaliptocultura (TUFFI SANTOS et al., 2006). O primeiro ano de instalação da cultura é o período mais crítico (PITELLI;MARCHI, 1991), podendo refletir em decréscimos qualitativos e quantitativos na produção. Cantarelli et al. (2006) também relatam que a maior influência da competição das plantas daninhas no Pinus taeda dá-se nos primeiros anos, pois verificaram um incremento de 58,7\% em altura nas plantas sob controle químico, em comparação com a testemunha, que teve convivência com as plantas daninhas.

De acordo com Ramos (2004), recomenda-se o manejo químico, por ser a prática que causa menos efeitos negativos à fauna em geral, principalmente para os insetos, pois sabe-se que parte da diversidade é afetada principalmente pela capina mecânica, na qual foi constatada maior perturbação da comunidade Formicidae.

Dentre os produtos utilizados, destaca-se o herbicida glyphosate. O N-(fosfonometil) glicina (glyphosate) é um herbicida sistêmico de ação total, que inibe a enzima 5-enolpiruvil shiquimato-3-fosfato sintetase (EPSP sintetase ou EPSPS), e impede que a planta forme os aminoácidos fenilalanina, tirosina e triptofano, utilizados para a síntese de proteínas e, também, em alguns metabólitos secundários, como vitaminas, lignina e hormônios (BRADSHAW et al., 1997).

O glyphosate pode ser aplicado na fase de pósemergência das plantas daninhas, o que favorece operações em áreas de cultivo mínimo; além disso, exerce efetivo controle de grande número de espécies daninhas mono e dicotiledôneas, perenes e anuais, sendo um herbicida de curto período residual e rapidamente inativado no solo (MALIK et al.,1989). É um herbicidas não seletivo ao eucalipto, sendo o contato dessas moléculas com a cultura, principalmente via deriva, altamente indesejado (TUFFI SANTOS et al., 2006).
Os herbicidas de translocação simplástica como o glyphosate são aqueles que translocam predominantemente pelo simplasto, ou seja, pelo conjunto vivo e contínuo, formado pelos protoplastos da planta, onde o floema faz parte do simplasto da planta (VICTORIA FILHO, 1987). Entretanto, pouco se sabe sobre os efeitos da deriva desse herbicida na cultura do eucalipto, nesse contexto, este trabalho teve como objetivo verificar a intoxicação, bem como o crescimento de plantas submetidas à de subdoses de glyphosate e sua absorção em diferentes locais de aplicação na planta.

\section{MATERIAL E MÉTODOS}

Este trabalho foi realizado em casa de vegetação no NUPAM (Núcleo de Estudos Avançados em Matologia), pertencente à Faculdade de Ciências Agronômicas - UNESP, campus de Botucatu/SP, entre outubro de 2007 e fevereiro de 2008. Para a produção das mudas de Eucalyptus grandis, oriundas de semente, foram utilizados tubetes cilindro-cônicos de polietileno com volume de $50 \mathrm{~cm}^{3}$, preenchidos por substrato, possuindo uma adubação de base contendo macro e micronutrientes. Essas mudas foram padronizadas em mesma altura e condições morfológicas visuais, com três meses de idade, sem rustificação, plantadas uma muda por vaso com $7 \mathrm{~L}$ de volume de solo. A adubação foi realizada de acordo com a recomendação para a cultura.

Antes da aplicação das gotas, determinou-se a área foliar média de 15 plantas, através de um medidor digital de área foliar “Areamiter” para estimar o volume de calda a ser aplicada. A aplicação dos tratamentos químicos foi efetuada quando as plantas estavam com 60 a $90 \mathrm{~cm}$ de comprimento, com o auxílio de uma micropipeta, sobre a face adaxial de três folhas, no caule e na planta inteira (folha + caule), dividindo-se o volume nos dois locais de aplicação.

As plantas de eucalipto receberam as subdoses de 40; 80; 160 e 240 g e.a.ha ${ }^{-1}$ de glyphosate, simulando uma deriva aplicada como solução aquosa da formulação comercial Scout ${ }^{\circledR}$. As plantas testemunhas não receberam nenhum tipo de aplicação. Utilizou-se o delineamento inteiramente casualizado, com quatro repetições, sendo cada vaso considerado uma parcela experimental disposta em um esquema fatorial 4 X 3 (quatro subdoses de glyphosate por 3 locais de aplicação), além de uma testemunha sem a aplicação de herbicidas.

Revista Árvore, Viçosa-MG, v.35, n.3, Edição Especial, p.589-594, 2011 
A aplicação foi realizada dia 18/01/2008, a umidade relativa do ar era de $86 \%$ e a temperatura de $26^{\circ} \mathrm{C}$. Avaliações visuais de controle foram realizadas aos 3, 7, 14, 21, 28 e 35 dias após a aplicação dos tratamentos, através de uma escala de percentual de notas, no qual 0 (zero) correspondeu a nenhuma injúria demonstrada pelas plantas e 100 (cem), a morte das plantas, segundo a Sociedade Brasileira da Ciência das Plantas DaninhasSBCPD (1995).

No final da ultima avaliação visual de fitotoxicidade, foram medidos a altura, o diâmetro e a área foliar das plantas. A parte aérea foi cortada rente ao solo, acondicionadas em estufa de ventilação forçada de ar para secagem por 72 horas, em temperatura de $60^{\circ} \pm 2^{\circ} \mathrm{C}$. Em seguida, as plantas foram retiradas e pesadas para a determinação da massa seca. A altura e o diâmetro também foram medidos no momento da aplicação para se ter o ganho desses parâmetros no final do experimento.

Os resultados encontrados foram submetidos à análise de variância pelo teste F e a análise de regressão pelo programa Sisvar, sendo adotados os modelos de regressão linear e polinomial, os quais apresentaram significância menor ou igual a 5\% de probabilidade.

\section{RESULTADOS E DISCUSSÃO}

Na Figura 1, estão apresentados os resultados da fitotoxicidade visual das plantas de Eucalyptus grandis após aplicação das subdoses de glyphosate. Aos 3 DAA, observaram-se os maiores sintomas de intoxicação(\%) em plantas que receberam aplicação no caule de $11 \%$, na maior dose utilizada, e não ocorreram diferenças entre as aplicações na folha e folha + caule. Nas subdoses de 40 e $80 \mathrm{~g} \mathrm{ha}^{-1}$ de glyphosate, não houve diferenças entre os locais de aplicação, porém, com a subdose de $160 \mathrm{~g} \mathrm{ha}^{-1}$, plantas com aplicação no caule também apresentaram os maiores valores de fitotoxicidade, pois, com aplicação nas folhas, houve apenas $2,4 \%$, e na folha + caule, $7 \%$. Foram mantidas as mesmas injúrias com o aumento da dose.

Aos 7 DAA, nas aplicações apenas sobre as folhas, houve leves sintomas de fitotoxicidade (variando de 0 a 20\%), mesmo quando utilizou-se a dose de $240 \mathrm{~g} \mathrm{ha}^{-1}$. Independente do local de aplicação, com a subdose de $40 \mathrm{~g} \mathrm{ha}^{-1}$, também observaram-se baixos valores de intoxicação; com a subdose de $80 \mathrm{~g} \mathrm{ha}^{-1}$ aplicada sobre caule e folha + caule, houve 19 e 33,4\%, respectivamente. Com 50\%, a maior subdose, houve a morte dos ponteiros e necrose nas folhas mais velhas, como verificado por Tuffi Santos et al. (2006), em plantas tratadas com glyphosate, que apresentavam murcha, cloroses e necroses, sintomas verificados a partir do sexto dia após a aplicação, sendo mais pronunciados nas subdoses superiores a $172,8 \mathrm{~g} \mathrm{ha}^{-1}$ de glyphosate.

Nota-se que, aos 14 DAA, ocorreu os maiores sintomas de injúrias na maioria dos tratamentos, atingindo valores entre 70 e $75 \%$ com as aplicações no caule e folha + caule, observando-se, além de morte de ponteiros, necrose no caule. Com a aplicação de $40 \mathrm{~g} \mathrm{ha}^{-1}$ sobre as folhas, não se observou intoxicação, atingindo 35\% na maior dose. Aos 21 DAA, nos tratamentos com aplicações sobre as folhas e caule, os valores da fitointoxicação mantiveram-se, e, nas folha + caule, houve uma pequena redução de até 7\%.

Registra-se, aos 28 DAA, que as plantas apresentaram leve diminuição nos sintomas de intoxicação. Nos tratamentos com aplicação no caule e folha + caule, observaram-se valores próximos a 55\% de injúria com a subdose de 240 g. ha-1 . Já com a dose de $160 \mathrm{~g} \mathrm{ha}^{-1}$ sobre o caule e nas folhas + caule, foram atingidos os valores de $39 \%$ e $48 \%$, respectivamente. Com a utilização das subdoses 40 e $80 \mathrm{~g} \mathrm{ha}^{-1}$, os valores estabilizaram-se, permanecendo próximos aos da avaliação de 21 DAA.

Aos 35 DAA, todos os tratamentos apresentaram redução de fitotoxicidade, exceto nas aplicações realizadas no caule e folha + caule com a subdose de $240 \mathrm{~g} \mathrm{ha}^{-1}$, observando-se valores entre 51 e 55\%, respectivamente. Esses resultados de maiores injurias quando a aplicação foi realizada no caule indicam que esse herbicida se movimenta muito rápido pela planta, e esse movimento está associado às velocidades de transporte de açúcares no floema, que são elevadas e, em geral, podem variar de 0,3 a 1,5 m h-1 (TAIZ; ZEIGER, 2004).

Devido à fitotoxicidade observada nas primeiras semanas de avaliação, a aplicação das subdoses de glyphosate em diferentes locais das plantas provocou redução em seu crescimento e desenvolvimento com a queima de ponteiro, necrose das folhas mais velhas e de partes do caule, o que pode ter ocasionado diminuição dos parâmetros avaliados. Na Figura 2, têm-se os valores médios de incremento de altura de plantas, no qual se observou um ganho de 1,2 cm em relação à testemunha, na aplicação de $40 \mathrm{~g} \mathrm{ha}^{-1}$ sobre as folhas. Nas aplicações no caule e na planta inteira, independente da dose 

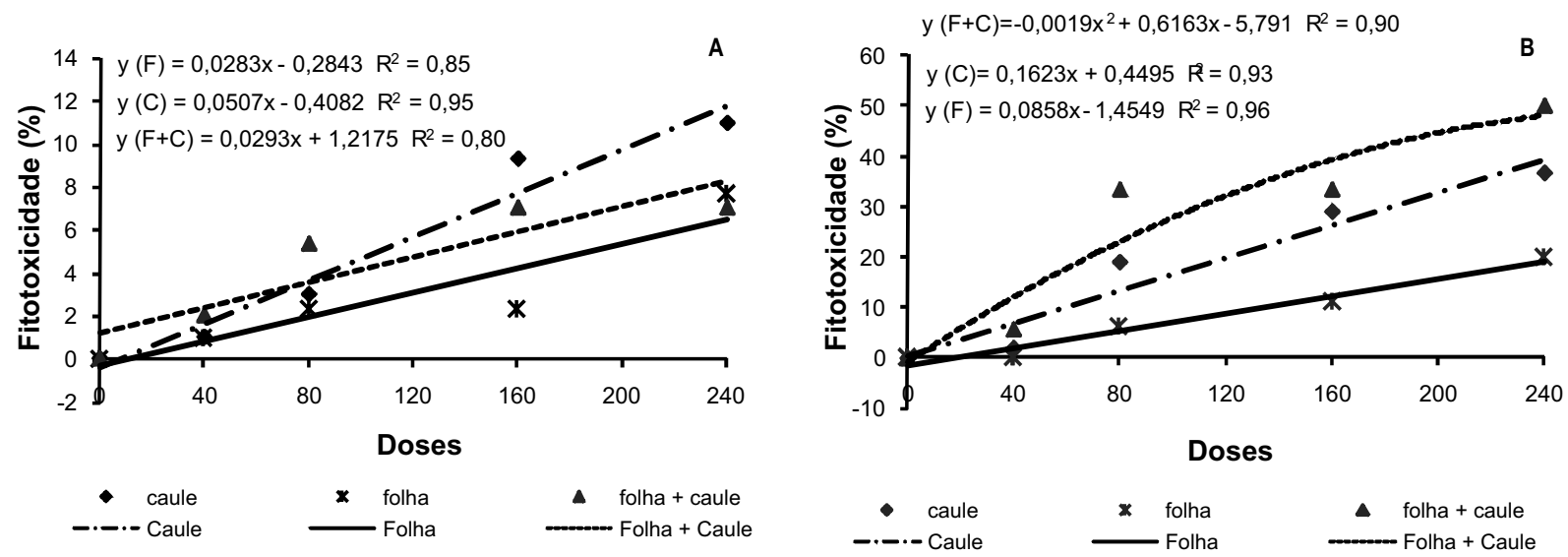

$y(F+C)=-0,0014 x^{2}+0,6715 x-5,9564 R^{2}=0,96 \quad C$
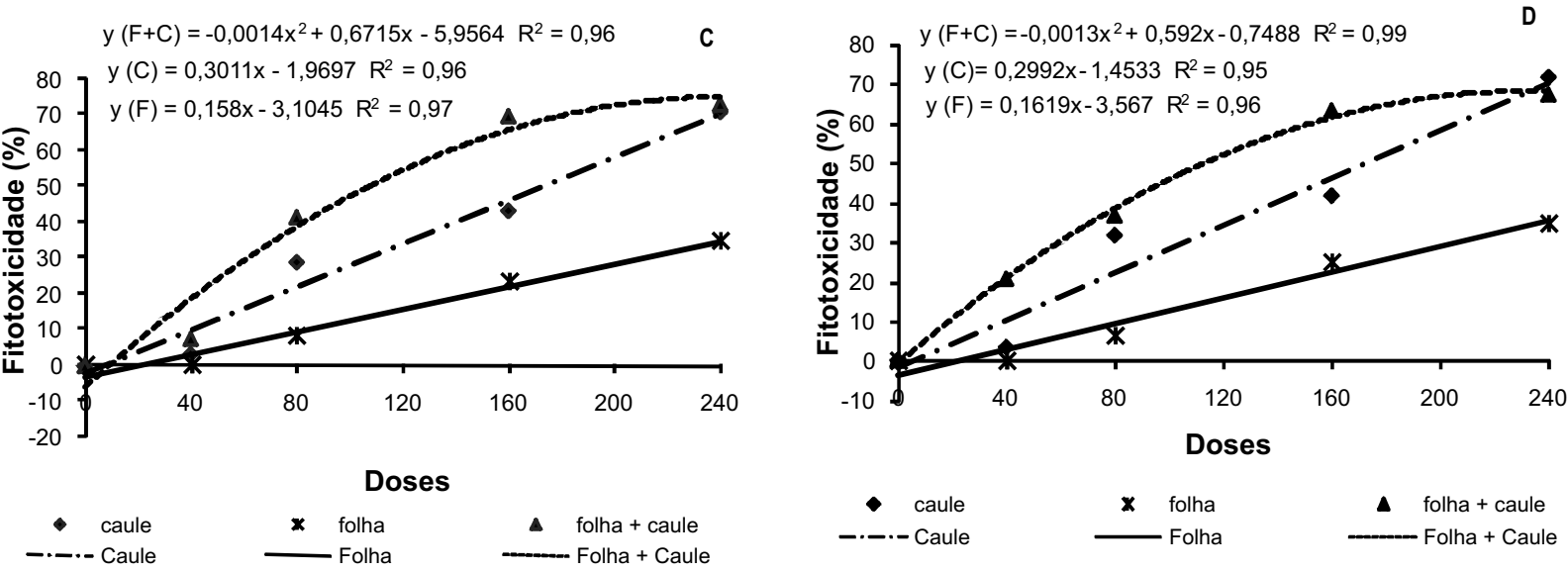

$y(F+C)=-0,0009 x^{2}+0,4195 x+3,3513 R^{2}=0,94 \quad E$
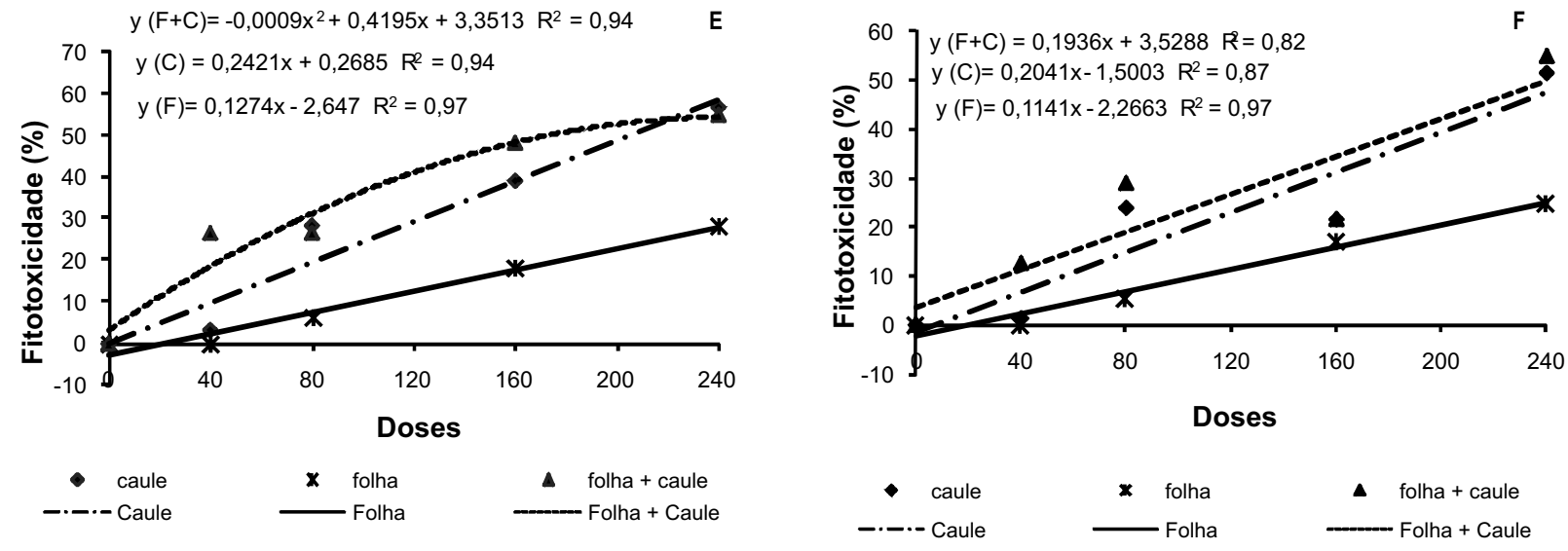

Figura 1 - Fitotoxidade visual (\%) das plantas de eucalipto submetidas a diferentes doses de glyphosate em três locais da planta: folha, caule e planta inteira (folha + caule), avaliados aos 3 (A), 7 (B), 14 (C), 21 (D), 28 (E) e 35 dias após aplicação (F). Botucatu/SP, 2008.

Figure 1 - Visual phytotoxicity (\%) of eucalyptus plants submitted to different doses of glyphosate in three locations of the plant: leaf, stem and whole plant (leaf + stem), evaluated at 3 (A), 7 (B), $14(C), 21$ (D), 28 (E) and 35 days after application (F). Botucatu / SP, 2008.

Revista Árvore, Viçosa-MG, v.35, n.3, Edição Especial, p.589-594, 2011 

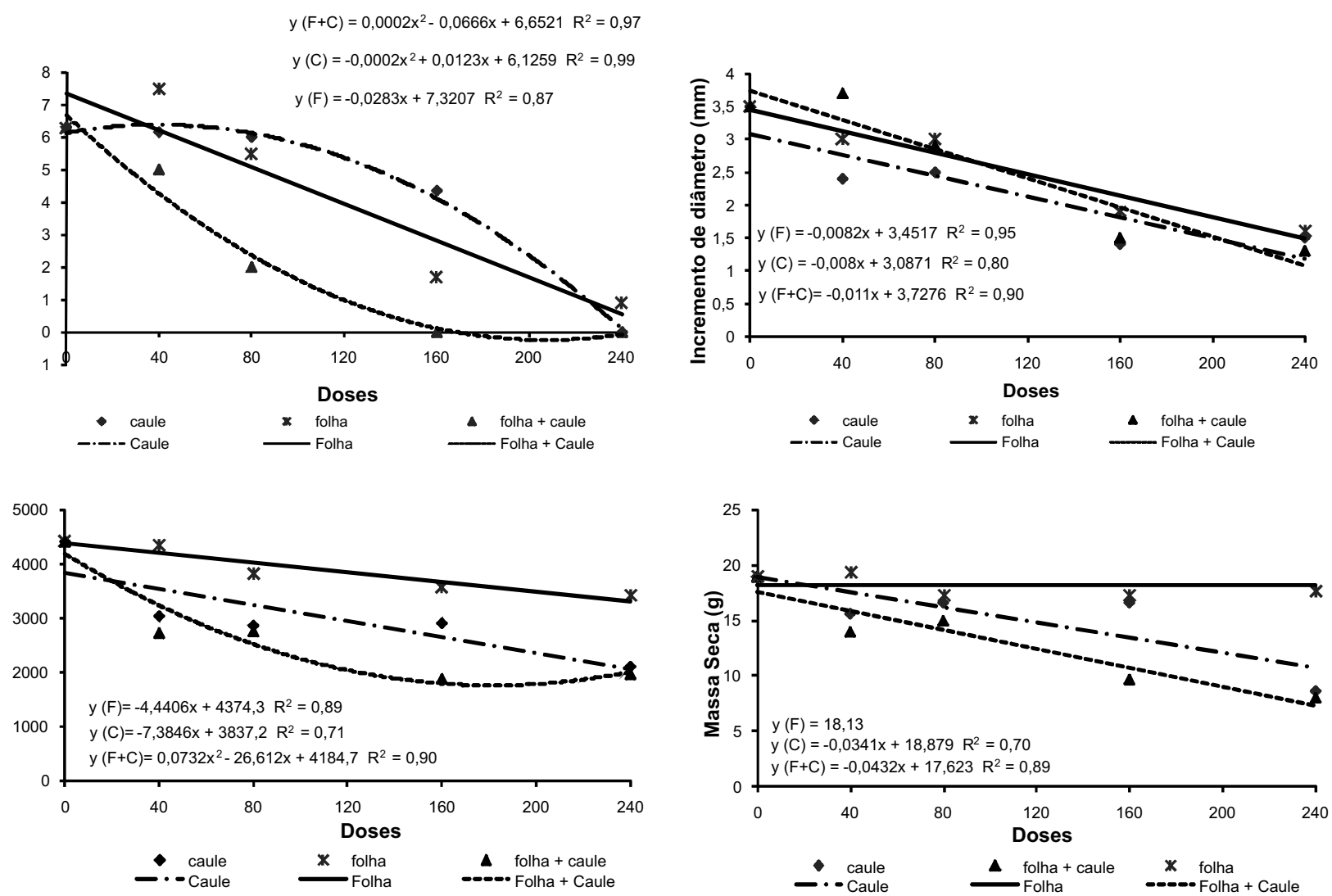

Figura 2 - Incremento de altura e diâmetro, área foliar e massa seca de plantas de Eucalyptus grandis sob deriva de diferentes doses de glyphosate em três locais de aplicação folha, caule e planta inteira (folha + caule), aos 35 dias após a aplicação. Botucatu/SP, 2008.

Figure 2 - Increase in height and diameter, leaf area and in dry mass of plants of Eucalyptus grandis submitted to drift of different doses of glyphosate on three sites of application: leaf, stem and whole plant (leaf + stem), at 35 days after application. Botucatu / SP, 2008.

ou do local de aplicação, houve redução de até 6 cm. Considerando que esse herbicida foi aplicado em uma única folha, é possível comprovar a rápida translocação do produto por toda a planta, como relatado por Ferreira et al. (2006), que trabalharam com azevém, aplicando glyphosate em uma única folha, e observaram a morte de todos os perfilhos.

Houve um incremento no diâmetro de caule em todos os tratamentos aplicados, mantendo valores médios abaixo do atingido por plantas sem aplicação de herbicida. Em aplicações com a subdose de $40 \mathrm{~g} \mathrm{ha}^{-1}$ sobre folha + caule, observaram-se um aumento de 0,2 cm no diâmetro, comparando com a testemunha, e menores diâmetros nas aplicações sobre o caule. Este comportamento manteve-se com as outras subdoses, o que pode ser explicado pela aplicação ter sido realizada diretamente sobre o caule, o que resultou na formação de grandes áreas necrosadas.

No final de 35 dias após a aplicação, os sintomas de injúrias em alguns tratamentos não foram mais observados e o crescimento das plantas não ficou comprometido, como em aplicação nas folhas, pois, independente das doses utilizadas, não houve diferenças na massa seca das plantas. Quando a aplicação foi realizada no caule e folha + caule, foram observados uma redução de até $26 \%$ na menor subdose e de até 58\% na maior subdose, comparando-se com os valores de massa da testemunha. 
A área foliar foi afetada conforme o aumento das subdoses utilizadas, havendo redução de 1,8\%, 32\% e $40 \%$ com a subdose $40 \mathrm{~g} \mathrm{ha}^{-1}$ nas aplicações sobre a folha, caule e folha + caule, respectivamente. Com a maior dose, esta redução chegou a 56\% nas aplicações sobre folha + caule, sendo este o tratamento mais prejudicado, pois houve um somatório de absorção do herbicida pelas folhas e caule. Aos 35 DAA, notou-se uma superbrotação, maioria de folhas pequenas e bifurcação dos ponteiros, o que pode prejudicar a qualidade final da madeira. Em um trabalho semelhante, com deriva de glyphosate em clones de eucalipto, Tuffi Santos et al. (2005) relatam a emissão de brotações normais e com sintomas de intoxicação em plantas expostas às subdoses de 172,8 e 345,6 $\mathrm{g} \mathrm{ha}^{-1}$ de glyphosate.

Com base nesses resultados, podemos inferir que o caule pode absorver e translocar maior quantidade de glyphosate para o resto da planta do que as folhas, devido à ação do produto, que interrompe o ciclo do carbono no cloroplasto, causando redução na síntese de carboidratos, diminuindo o transporte destes para os drenos e, consequentemente, diminuindo o transporte de glyphosate (MCALLISTER; HADERLIE, 1985), pois todos os resultados mostram menor taxa de distribuição do produto quando este foi aplicado somente na folha.

\section{CONCLUSÕES}

Nas condições em que foi realizado este trabalho, pode-se concluir que a possível deriva do herbicida glyphosate em subdoses acima de $80 \mathrm{~g} \mathrm{ha}^{-1}$ pode afetar negativamente o crescimento do eucalipto, diminuindo o ganho em altura de plantas e em diâmetro, massa seca da parte aérea e área foliar; os maiores prejuízos foram verificados na maior subdose utilizada (240 g ha $^{-1}$ ) em aplicação na planta inteira; os sintomas de fitotoxicidade foram maiores nas plantas de eucalipto quando o contato do glyphosate deu-se pelo caule/ folha + caule em comparação com a aplicação somente nas folhas; a partir dos 28 dias após aplicação, houve uma redução de sintomas de intoxicação, sendo mais discretos nas aplicações no caule e na planta inteira.

\section{REFERENCIAS}

BRADSHOW, L. D. et al. Perpectives on glyphosate esistence. Weed Tecnology, v.11, p.189-198, 1997.
CANTARELLI, E. B. et al. Efeito do manejo de plantas daninhas no desenvolvimento inicial de Pinus taeda em várzeas na Argentina. Revista Árvore, v.30, n.5, p.711-718, 2006.

FERREIRA, E. A. et al. Translocação do glyphosate em biótipos de azevém (Lolium multiflorum). Planta Daninha, v.24, n.2, p.365-370, 2006.

MALIK, J.; BARRY, G.; KISHORE, G. The herbicide glyphosate. Biofactors, v.2, p.17-25, 1989.

MCALLISTER, R.; HABERLIE, L.L. Translocation of ${ }^{14} \mathrm{C}$-Glyphosate and ${ }^{14} \mathrm{CO}_{2}$ - Labeled photoasimilates in Canada thistle (Cirsium arvense). Weed Science, v.33, p.153-159, 1985.

PITELLI, R. A.; MARCHI, S. R. Interferência das plantas invasoras nas áreas de reflorestamento. In: SEMINÁRIO TÉCNICO SOBRE PLANTAS DANINHAS E O USO DE HERBICIDAS EM REFLORESTAMENTO, 3., 1991, Belo Horizonte. Anais...Belo Horizonte: SIF, 1991. p.1-11.

RAMOS, L. S. et al. Impacto das capinas mecânica e química do sub-bosque de Eucalyptus grandis sobre a comunidade de formigas (Hymenoptera: Formicidae). Revista Árvore, v.28, n.1, p.139-146, 2004.

TAIZ, L.; ZEIGER, E. Fisiologia vegetal. 3.ed. São Paulo: Artmed, 2002. 719p.

TUFFI SANTOS, L. D. et al. Intoxicação de eucalipto submetido à deriva simulada de diferentes herbicidas. Planta Daninha, v.24, n.3, p.521-526, 2006.

TUFFI SANTOS, L. D. et al. Crescimento e morfoanatomia foliar de eucalipto sob efeito de deriva do glyphosate. Planta Daninha, v.23, n.1, p.133-142, 2005.

VICTORIA FILHO, R. Série Técnica IPEF, v.4, n.12, p.36-44, 1987.

Revista Árvore, Viçosa-MG, v.35, n.3, Edição Especial, p.589-594, 2011 